\title{
Modeling Un-authorized Land Use Sprawl with Integrated Remote Sensing-GIS Technique and Cellular Automata
}

\author{
Norzailawati Mohd. Noor and Mazlan Hashim \\ Department of Remote Sensing, \\ Faculty of Geoinformation Sciences and Engineering, \\ Universiti Teknologi Malaysia, \\ 81300 Skudai, Johor Bahru, Malaysia \\ norzailawati@gmail.com, mazlanhashim@utm.my
}

\begin{abstract}
We have used cellular automata integrated with GIS and remote sensing to analyze urban sprawl aiming at analyzing expansion of potential unauthorized land uses for residential, commercial and industrial based on spatial factor deriving from remote sensing high resolution data. The spatial factors considered are used as parameter to measure either land use in these expansion process develop as urban legal sprawl or sprawl with declined the development planned (un-authorized). Results of the study indicated that residential area is most probable risk to un-authorized land use sprawl, given set of spatial factors considering the vicinity of highway strip, land use segregation and leapfrog development.
\end{abstract}

Keywords: Landuse sprawl modeling, remote sensing, GIS and Cellular Automata.

\section{Introduction}

The extent of urbanization or its growth drives the change in land use/cover pattern. Land use changes in chaotic sprawl phenomena could exert impacts on ecology of the area, especially environment nuisance, traffic congestion and resulting in increased of travel cost [8] [10] [12] [11] [25]. Accurate information on the extent of urban growth is of great interest for the municipalities of growing urban and suburban area for diverse purposes such as urban planning, water and land resource management, marketing analysis, service allocation, etc. Urban authorities and municipal corporations are required to devote more time, attention and effort to manage the use of land and other resources in order to deal with infrastructural needs due to the expansion population or other urban land uses. The expansion of urban sprawl prediction is the basic information needed for long term planning. In ensuring a balance development, municipal authorities need tools to monitor on the status on how the land is currently used, which land is possible to develop lack of development plan and possibility factors that are influencing of any sprawls, apart from devising steps to assure development is parallel with gazetted plan. In the context of sound 
planning, municipal authorities need to know urban sprawl phenomenon and should be able to plan for future development once the predictive sprawls be known.

Cellular automata (CA) are powerful spatial dynamic modeling techniques that have been widely applied to model many complex dynamic systems. Recently, variety of urban CA models have been developed to simulate urban phenomena either artificial or realistic cities. CA model can provide procedures for the design of optimal forms [2]. They may become powerful tools when integrated with geographical information system (GIS) and Remote sensing data, which can supply physical, social and economic data for simulation [12] [27] [23]. Recent CA models have generally been linked to GIS by using inhomogeneous array of cells so that the transition rules are, in a sense, site specific. Remote sensing and GIS are integrated with CA in providing detailed land use information as well as information on other characteristic of cities to allow realistic urban simulation [20].

Recently, attempts have been made to develop a kind of cellular automata model that can be used a model for urban planning [6] [20] [28] [26] [9]. We have used cellular automata integrated with GIS and remote sensing to analyze urban sprawl aiming at expansion of potential un-authorized land use (e.g residential, commercial and industrial) based on spatial factor deriving from remote sensing high resolution data.

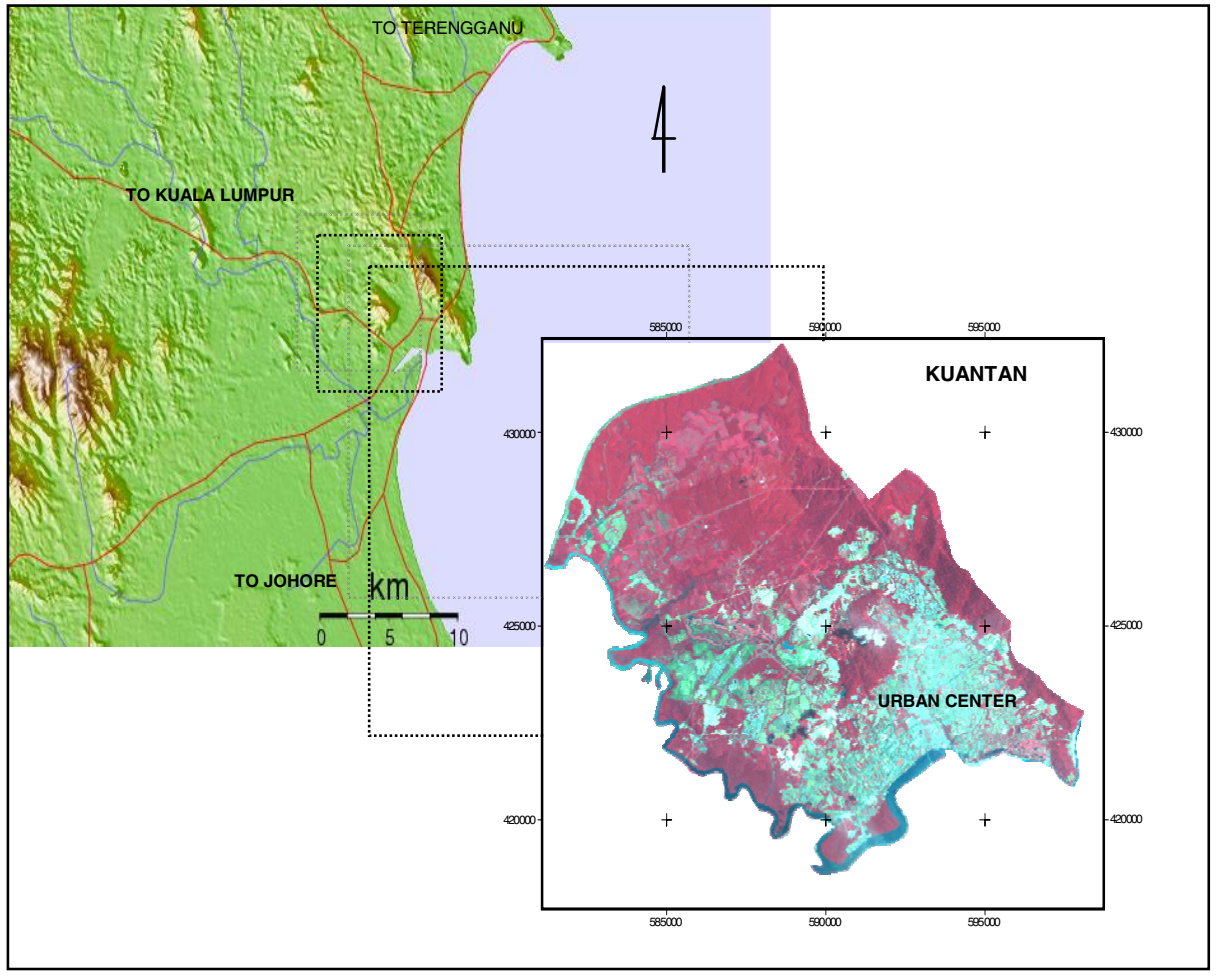

Fig. 1. Location of study area - Kuantan District, Malaysia 


\section{Study Area}

The study area is located in Kuantan district $\left(03^{\circ} 52 \mathrm{~N}, 103^{\circ} 17 \mathrm{E}\right.$ and $\left.03^{\circ} 45 \mathrm{~N}, 103^{\circ} 23 \mathrm{E}\right)$, Malaysia, covers an administrative area spreads over an area of 13,501 hectares. Majority of the land use pattern consist built-up areas (residential, industrial, commercial, institution, recreation area, road, infrastructure and utilities) and un-build (agriculture, forest, bare land and water bodies). Population of Kuantan was 106,704 in the year 2000, and it is projected to be 241,197 in 2015, as per the present growth rate (Kuantan Local Plan, 2004). For a better planning of future urban development and infrastructure planning, municipal authorities need to know sprawl phenomenon of Kuantan, its distribution, factors and in what way it likely to move in the years to come.

\section{Materials and Method}

\subsection{Satellite Data and Ancillary Information}

The data has been collected from primary and secondary data sources (Table 1). The data collected from the primary sources include topographic maps of the area, land use map, un-authorized development data and IKONOS pan-sharpened image for the year 2004. The ancillary information collected from secondary sources include road network, drainage pattern, cadastral map of alienated land parcels, urban map and records of unauthorized development.

Table 1. Different type of data used

\begin{tabular}{llc}
\hline No & Type of data used & $\begin{array}{c}\text { Year of acquisition } \\
\text { /Publication }\end{array}$ \\
\hline 1 & IKONOS satellite data (6 sets) & 2004 \\
2 & Topographic map & 1975 \\
3 & Land use Map & 2003 \\
4 & Road Map & 2003 \\
5 & Drainage Map & 2003 \\
6 & Cadastral Map (Land Lot) & 2003 \\
6. & Contour Line & 1975 \\
7 & Urban Map & 2004 \\
8 & Un-Authorized Development Data & 2004 \\
\hline
\end{tabular}

\subsection{Methods}

In order to understand the dynamic phenomenon of urban sprawl, the basic requirement is the availability of information on land use change, urban pattern identification and computatation of landscape metrics. In this study all these required information has been compiled and converted to digital forms and are readily used in both data processing in Digital Image Processing System and Geographic Information 
System. The ERDAS Imagine and Ecognition are two main Digital Image Processing used in the study, while ArcGIS software systems is the Geographic Information System used to generate various thematic layers consisting of Kuantan administrative boundaries, roads, contours and administrative boundary map using topo-sheet and other available maps. Complete methodology of the study is shown in Fig.2.

The image pre-processing and data preparation techniques are firstly carried out; these include image rectification and mosaicking. The image- to-map procedures has been applied to the IKONOS image using set of ground control points area appear in the same place both in the imagery and known locations in corresponding map and urban plan used as ancillary information in the rectification process. The rectified data sets are then mosaicked producing the entire study area from six sets of the raw IKONOS data.

Image classification is then applied to the pre-processed image, where the land use classes map of the entire study area is produced. The supervised classifications techniques have been choosen for this study, performed using object-based classifier using eCognition software system, which have enabled all fine details of land cover be classified, later merged accordingly to form the classes in accordance to urban land use classes used in urban planning practice.

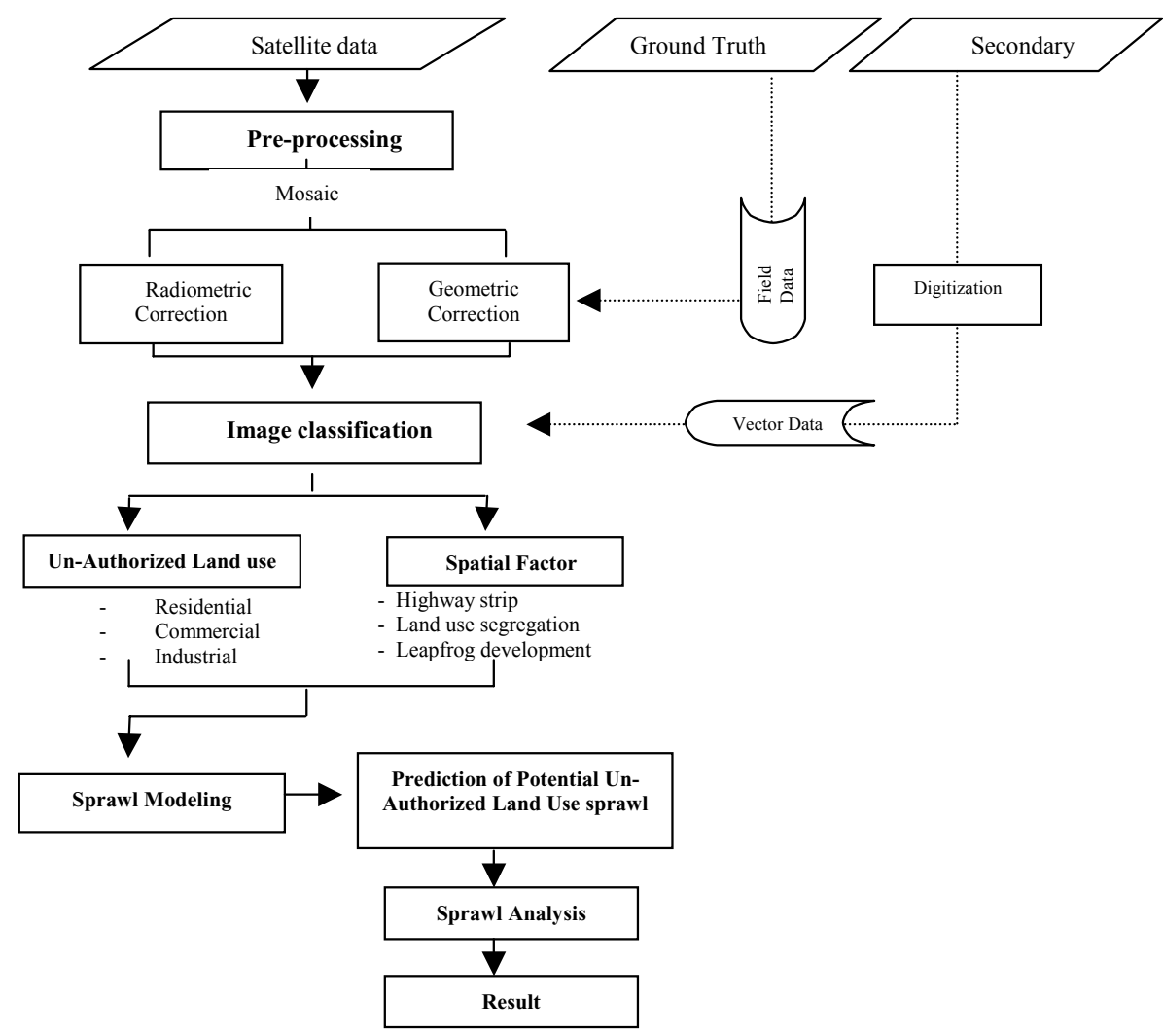

Fig. 2. Flowchart of data processing adopted in the study 
In this study the object-based classifier is employed to build optimal training areas and build-up knowledge for each classes of interest prior to classification of the entire image. Initially, the algorithm trains the spectral classes by supervised training process, after collection of parametric and non-parametric signatures (training samples). After completion of the training process, the entire knowledge on the class's occurrence within the IKONOS image is generated. The knowledge is then used to identify all the pixels of in the image into the trained classes with multiresolution segmentation approach. The classes identified were then re-categorized into two main classes of un-built and build-up, apart from identifying it further into detailed 10 land uses for 3 land use that have shown potential to expand or risk as unauthorized land use sprawl, namely the residential, commercial and industrial areas.

The spatial factors for all the 3 main land uses are then derived based on the proximity of the classes of interest to highway strips, segregation land use and leapfrog development. All the spatial factors obtained are then feed into the cellular automata (CA) sprawl model for the sprawl analysis.

The CA model was employed in the sprawl analysis where it is used to simulate the spatial pattern of urban sprawl in the residential, commercial and industrial areas of Kuantan which have been reported as to expand as un-authorized development. Using a three element of spatial factor the expansion of these land uses were defined based on 2004 data. Four basic elements of CA have been determined according cells, states, neighborhood and transition rules. Cell is intrinsically linked with the observed space to represent land parcel. Although the original pan-sharpened IKONOS had ground resolution of $1 \mathrm{x} 1 \mathrm{~m}$, the cells size was resampled to $10 \times 10 \mathrm{~m}$ for faster simulation and also support an average parcel size in imagery this study.

The state of each cell represented land use activities $\mathrm{L}_{\mathrm{ij}}$ which divided into seven categories of built up area (residential, commercial, industrial, institution and infrastructure \& utility, open space and recreation and transport) and un-built area comprises of agriculture, forest and vacant land. This model only dealt with urban and non-urban conversion. The algorithm of CA employed in this study is given equation (1) [24]. Neighborhood $\mathrm{Nt}_{\mathrm{ij}}$ in a CA-based model is consist of a window of predefined size and shape used to defined the sphere of influence for urban development with using $3 \times 3$ windows neighborhood. Transition rules was formulated to govern cell evolution, where cells state at any time step was determined by the state of cells at previous time step and suitability index calculated on the basis of factor influencing urban sprawl. Table 2 below summarized the sprawl analysis the 3 main prospective affected land use classes with the spatial factors used.

$$
\mathrm{Gt}_{\mathrm{ij}+1}=\int\left(\mathrm{Lt}_{\mathrm{ij}} \cdot \mathrm{Nt}_{\mathrm{ij}} \cdot \mathrm{T}_{\mathrm{r}}\right)^{\mathrm{t}}
$$

where

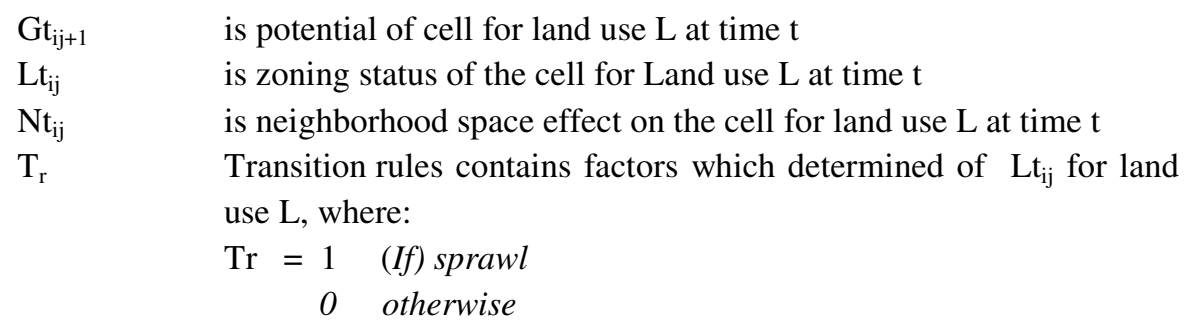


Table 2. Parameter for spatial factors

\begin{tabular}{lll}
\hline Spatial Factors & Parameters & Weightage \\
\hline $\begin{array}{l}\text { Land use segregation } \\
\begin{array}{l}\text { ( number of different Land use } \\
\text { within parameter) }\end{array}\end{array}$ & $>1500 \mathrm{ft}$ & $\begin{array}{l}\text { Un-Authorized Sprawl } \\
\text { Common Development }\end{array}$ \\
\hline $\begin{array}{l}\text { Highway Strip } \\
\text { (walking Distance) }\end{array}$ & $>300 \mathrm{ft}$ & $\begin{array}{l}\text { Un-Authorized Sprawl } \\
\text { Common Development }\end{array}$ \\
\hline $\begin{array}{l}\text { Leapfrog } \\
\left(\sum \text { number of land use within }\right. \\
\text { dinstance) }\end{array}$ & $>500 \mathrm{ft}$ & Un-Authorized Sprawl \\
\hline
\end{tabular}

Source: modified from Hasse, 2004

The highway strip measure was calculated in this analysis by determining whether a new development unit occurred within a $100 \mathrm{~m}$ buffer of a main road. The development areas within the highway buffer were assigned as common development, whereas housing units outside the buffer in this contact of this study assigned as unauthorized sprawl. The segregated land use index, as developed in this analysis, measure the degree to which land use is mixed at a pedestrian scale. It is a measure of the number of different types of land uses that are within reasonable walking distance to a housing unit. Nelessen (1994) suggests that $1500 \mathrm{ft}$ (the distance that an average pedestrian will walk in 10 minutes) constitutes reasonable walking distance [22]. The index was calculated by counting the number of different land use types within $1500 \mathrm{ft}$ of unit as buffered in maps. The leapfrog index was calculated in this analysis by a straight-line distance measurement using $1500 \mathrm{ft}$ walking distance from each housing unit to the perimeter of the nearest land use area. If there more than three land uses, this was consider well development and otherwise if that area have less than three types of land uses.

\section{Results and Discussion}

\subsection{Image Analysis}

The 6 sets of IKONOS imagery have been successfully merged altogether and geometrically corrected with transformed to local mapping coordinate with RMSE \pm 0.5 pixel to ensure accuracy of the sprawl analyzed. In fact this RMSE had been widely used a good practice in ensuring good geometric output apart from ensuring sound configuration of ground control point, evenly distributed in the study area. Fill this imagery also subjected to image enhancement respectively.

The image classification carried out in two steps process to produce first level classes of built and un-build areas, and further detailed land use classes within the built-up areas. Final classified image classes were tabulated as in Table 3.

The corresponding vector layer of land parcels was used as contextual information in labeling level of the classified spectral class in GIS system. The rule is only one class (label) output is allowed for each polygon at spectral classes within land parcel (Land Lot). The result of classification is shown as figure 3. The assessment of the classification is carried out based on the classified image with the in situ information. 
Table 3. Land use classified for year 2004

\begin{tabular}{lrc}
\hline Land Use Classes & Area (ha) & Percent \\
\hline Residential & $10,203.5$ & 75.6 \\
Commercial & 1256.9 & 9.3 \\
Industrial & 365.0 & 2.7 \\
Institution & 135.2 & 1.0 \\
Infrastrucure and Utility & 67.5 & 0.5 \\
Open area and recreation & 135.2 & 1.0 \\
Transportation & 40.5 & 0.3 \\
Forest & 81.1 & 0.6 \\
Agriculture & 540.6 & 4.0 \\
Vacant Land & 675.7 & 5.0 \\
\hline TOTAL & $\mathbf{1 3 5 0 1}$ & $\mathbf{1 0 0}$ \\
\hline
\end{tabular}

Table 4 below summarizes the accuracy of IKONOS image classification for the urban land use. An overall classification accuracy of over $85 \%$ have been achieved with Kappa 0.86 . This is indeed very good classification confirmed with significant test.

Table 4. Result of paired Samples T-test ( Correlation)

\begin{tabular}{|c|c|c|c|c|c|c|}
\hline & \multicolumn{5}{|c|}{ Paired Differences } & \multirow{3}{*}{ Correlation } \\
\hline & \multirow[t]{2}{*}{$\begin{array}{l}\text { No.Of } \\
\text { Class }\end{array}$} & \multirow[t]{2}{*}{ Std. } & \multirow[t]{2}{*}{$\begin{array}{l}\text { Std. } \\
\text { Error } \\
\text { Mean }\end{array}$} & \multicolumn{2}{|c|}{\begin{tabular}{llr}
\multicolumn{1}{c}{$95 \%$} & \multicolumn{2}{c}{ Confidence } \\
Interval of the \\
Difference
\end{tabular}} & \\
\hline & & & & Lower & Upper & \\
\hline $\begin{array}{l}\text { Pair 1 } \\
\text { Existing - } \\
\text { Image }\end{array}$ & 11 & 125.35 & 37.80 & -84.2108 & 84.2108 & .995 \\
\hline
\end{tabular}

\subsection{The Sprawl Simulation}

The main aim of the sprawl analysis is to tract urban expansion based on land uses potential to grow as un-authorized sprawl. The model generation for sprawl in this study area has been translated through model builder in ArcGIS 9.2. The four elements of cellular automata model (cells, state, neighborhood and transition rules) have been integrated using tools in ArcGIS to generate a future 2015 urban scenario. The Arctools of greater than equal $=$ transition rules and focal statistic = neighborhood were integrated to produce the land use projection based on land use in 2004 and projection in year 2015. Fig 4 shows the simulated sprawl for 2015 for the residential, commercial and industrial area. 


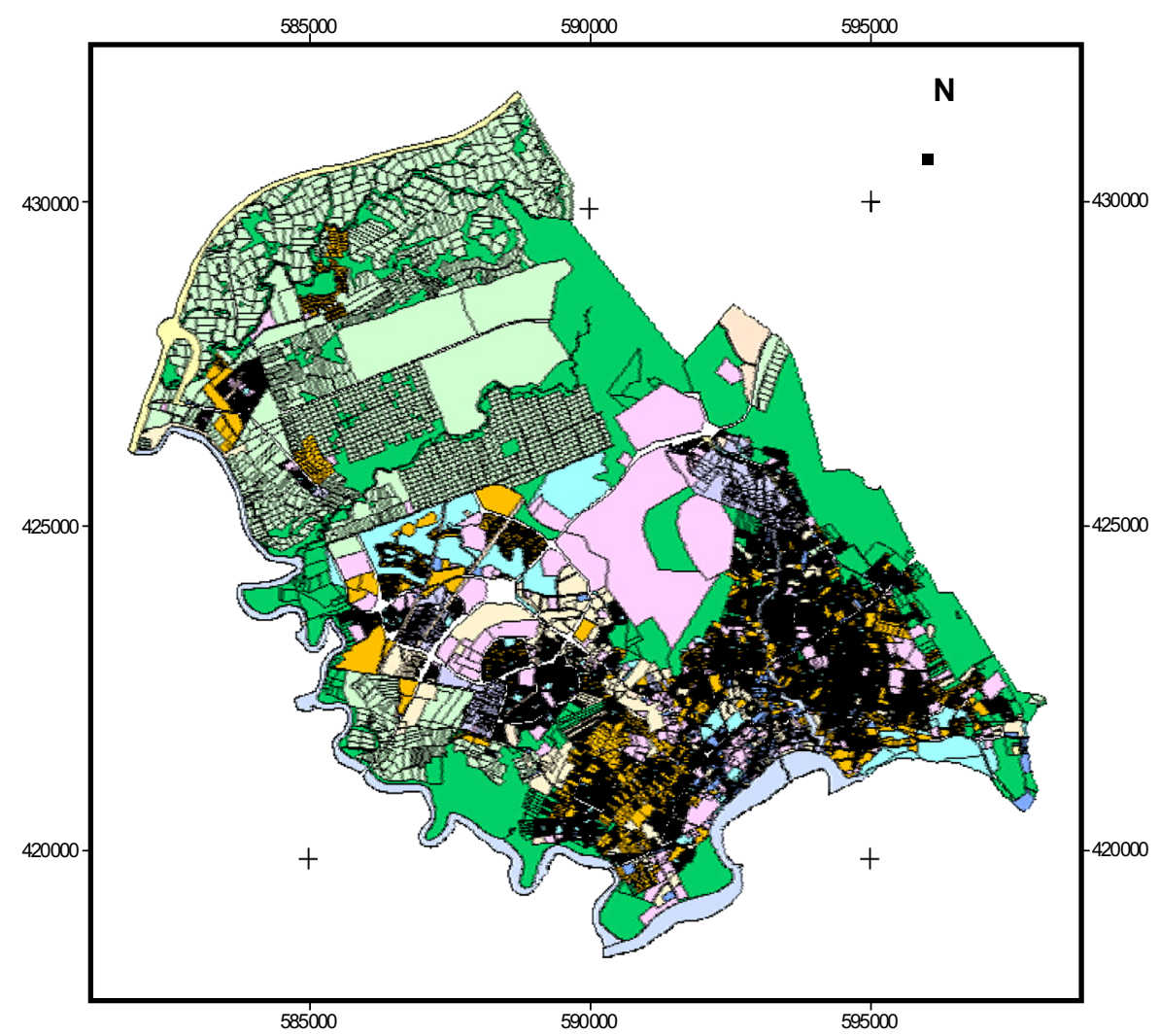

Legend:

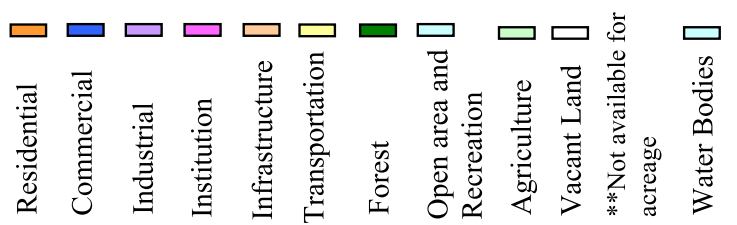

Fig. 3. Land use map of Kuantan generated from IKONOS image classification acquired in 2004

Fig 4 also shows the entire sprawl of the un-authorized land use expansion modeled for the residential, commercial and industrial areas. These expansions of sprawl follow the rule of conversion from non-urban to urban. Residential area has the higher number of sprawled due to un-authorized development but have the small number for growth percentage possibility due to role of urban as commercial center. This is very much related to the expansion of within commercial area which shows higher growth while in the industrial land use was shrunk by $(12 \%)$ due to the decrease in sprawl projected for 2015 . 


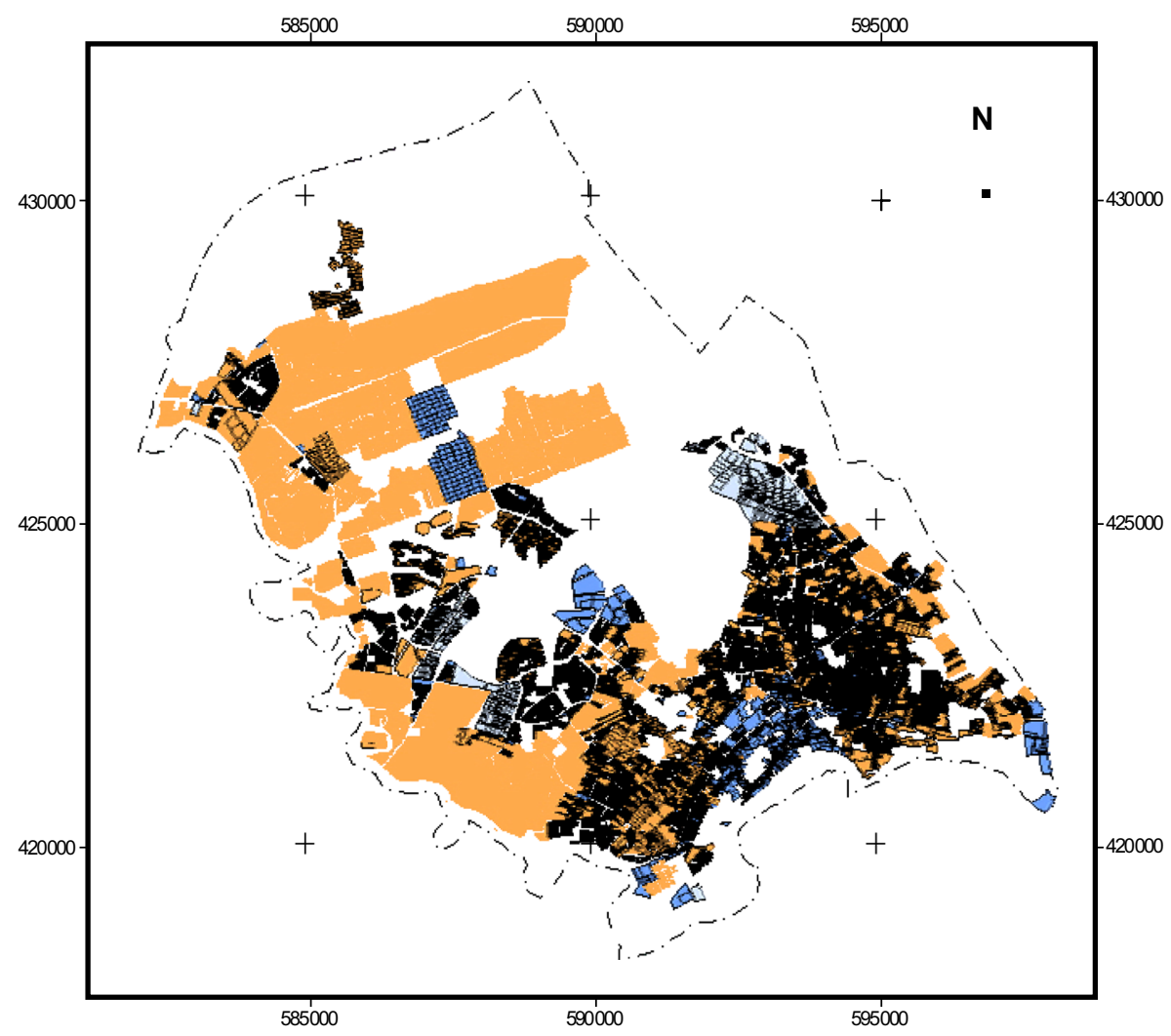

\section{Legend: \\ $\square$ Residential \\ $\square$ Commercial \\ $\square$ Industrial}

Fig. 4. Projected un-authorized land use sprawl for residential, commercial and industrial in Kuantan in 2015

Table 5. Summary of total Land use change from actual to expected based on potential to expand as un-authorized development

\begin{tabular}{lccc}
\hline $\begin{array}{l}\text { Year } \\
\text { /Types of Land use }\end{array}$ & $\begin{array}{c}\text { Residential } \\
\text { (ha) }\end{array}$ & $\begin{array}{c}\text { Commercial } \\
\text { (ha) }\end{array}$ & $\begin{array}{c}\text { Industrial } \\
\text { (ha) }\end{array}$ \\
\hline Actual year 2004 & 10203 & 1257 & 365 \\
Expected Year 2015 & 11122 & 1554 & 324 \\
\hline \% of Changes & $9 \%$ & $23.6 \%$ & $-12 \%$ \\
\hline
\end{tabular}

Based on neighborhood rules in simulation, the conversion of this land use is actually convert the non-urban types such as agriculture, vacant land and forest to the urban area and three of this land use is apart from that. 


\subsection{The Analysis of Sprawl}

The analysis of sprawl projection is to assess the characteristic of expansion of land use based on spatial factors. These spatial factors have been formulated to determine either sprawls occurrence is un-authorized or only common development that already being gazetted. Based on distance set in the model implementation, information of these land use were buffered and the area and number of land use have been calculated. The result of determination of land uses as shown below:

\subsubsection{Analysis of Parameter}

The land use in the main road of study area has been calculated and the changes for year 2004 and 2015 shown as in Fig 5. Results show that the development for

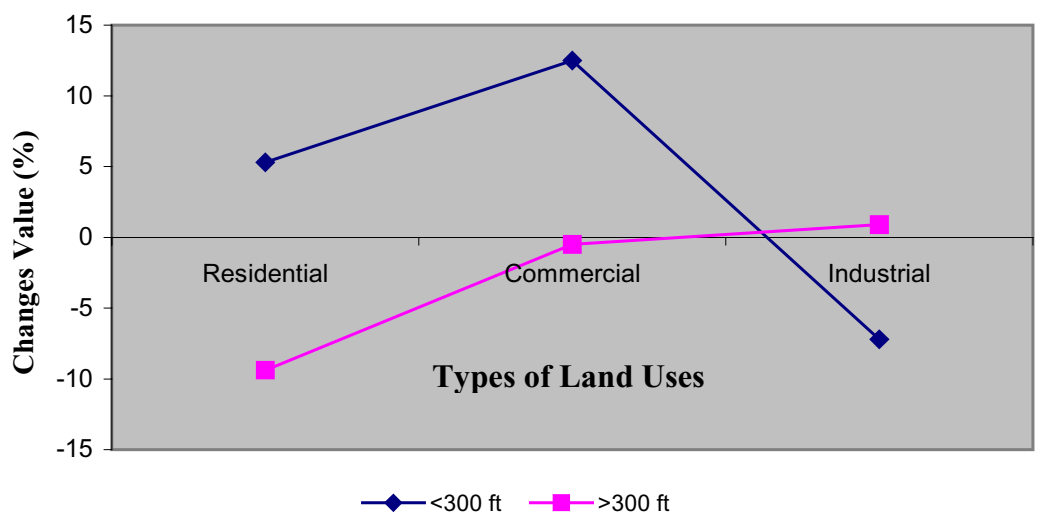

(a) Highway Strip

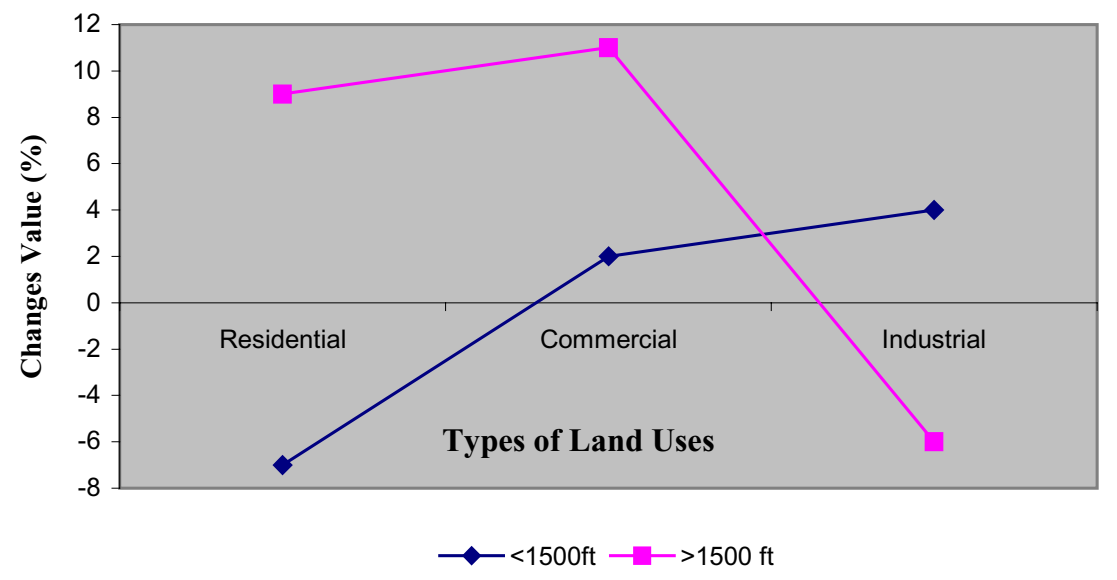

(b) Segregation of Land Used

Fig. 5. Land use changes for both year (2004 and 2015) based on spatial parameter of (a) highway strips and (b) segregation of land use, respectively 
commercial was commonly centered in road tracts. In the buffer of less than $100 \mathrm{~m}$, the commercial have a higher value and decreases outside the buffered zones. The opposite trends are shown in the case of both the residential and industrial areas. Sprawls modeled as shrunkage for the 3 areas within buffer larger than 100m, could be attributed due to the concentration of development in along the road based on economic activities generated by commercials categories. This observations also described that the element of highway strip also has brought quite an influence to the expansion of un-authorized land uses in outer buffered area which available and evidently shown during our field verifications being developed into agriculture or remained as scrubs or secondary forest within the suburbans.

While analysis on segregation land uses show that over the walking distance, residential and commercial have a potential to expand as sprawl rather than industrial area. This phenomenon is due to the economic factors which attract investors to build new area from vacant land from central urban area in avoidance of congestion and privacy preferation.

Analysis for leapfrog development show there more than 3 types of land uses at a distance of $300 \mathrm{~m}$ (Table 6). Using the residential as a focal point, the number of individual development units has been calculated. The results show all points have only 2 mains types of land uses domain in the area. This represent the area that was segregated with each other and have potential to expand as sprawl due to centralized to all other types of land use.

Table 6. Types of development at 500m distance from residential point

\begin{tabular}{ccccccc}
\hline & & & & \\
\hline
\end{tabular}

The above results have demonstrated on the un-authorized land use expansion as sprawls, modeled with CA with using fixed selected parameter for the spatial factors. Each parameter have their own influence to attract land uses as sprawl, particularly on highway strips. The development along the main road commonly found in the urban scenario. The accessibility of transportation to mobile in other places attracts people to build and centre at this area. While the segregation and leapfrog development has a similarity from the location of land use types which have a potential to spread as sprawl. 


\section{Conclusion}

The urban sprawl is seen as one of the potential challenge to sustainable development where urban planning with effective resource utilization, allocation of natural resources and infrastructure are the key concerns. The study attempted to analyze potential un-authorized land uses to expand as a sprawl based on prediction of land uses for 2015 using Cellular automata Model. Remote sensing and GIS techniques have been used to demonstrate their application for the monitoring and modeling of dynamic phenomena. The spatial and attribute data of the region have been aided in statistical analysis and defining few of the spatial factors. These spatial factors and relationship between urban sprawl and some causative factors are useful for the local development authorities and municipalities to determined spatial distribution authorities. The integrative approach of remote sensing, GIS with sprawl model evident create sound analysis for sprawl.

\section{References}

1. Ahn, T.-M., Choi, H.-S., Kim, I.-H., Cho, H.-J.: A Study on the Method of Measuring Accessibility to Urban Open Spaces. Journal of the Korean Institute of Landscape Architecture 18(4), 17-28 (1991) (in Korean)

2. Bach, L.: The Problem of Aggregation and Distance for Analysis of Accessibility and Access Opportunity in Location-Allocation Models. Environment and Planning A 13, 955973 (1981)

3. Byun, B., Lee, B.-J.: Strategies for Conserving Green Spaces for a Pleasant Urban Environment. Korea Environment Institute, Seoul (2002) (in Korean)

4. Choi, M.-J., Kim, S.-K.: Estimation of Residential Location Demand Based on the Modified Potential Model Incorporating both Employment and Open Space Accessibility. Journal of the Korea Planners Association 37(2), 55-63 (2002) (in Korean)

5. De Clercq, E.M., Wulf, R.D., van Herzele, A.: Relating Spatial Pattern of Forest Cover to Accessibility. Landscape and Urban Planning 80, 14-22 (2007)

6. Eom, S., Cho, C., Choi, Y.: The Study of Estimating Total Greenspace on the Seoul Metropolitan by the Location-Allocation Model. The Korea Spatial Planning Review 56, 61-78 (2008) (in Korean)

7. Eom, S., Lee, S.: Development and Application of an Assessment Model of Greenspace A Case Study for Pyeongchon and Sanbon Newtown. Journal of the Korea Planners Association 43(3), 263-273 (2008) (in Korean)

8. Kwon, S.-Z., Kim, Y.-I.: A Study on Dividing the Enticing Area According to the Catchment of Urban Community Parks. Journal of the Korean Institute of Landscape Architecture 19(3), 98-127 (1993) (in Korean)

9. Lautso, K., Spiekermann, K., Wegener, M., Sheppard, I., Steadman, P., Martino, A., Domingo, R., Gayda, S.: Planning and Research of Policies for Land Use and Transport for Increasing Urban Sustainability. Final Report, LT Consultants, Finland (2004)

10. Lee, S.: A Study of the Analysis of Relation between Sustainable Urban Form and Urban Traffic Problems for the Urban Region of Kwangju. The Korean Transport Policy Review 6(1), 45-74 (1999) (in Korean)

11. Lee, S.: Sustainable Development and Amendment of Korean Urban Planning Law. The Korea Spatial Planning Review 29, 97-112 (2000) (in Korean) 
12. Lee, S.: Road Traffic Noise Immission Calculation Model Using Raster-GIS. Journal of the Korea Planners Association 36(3), 163-176 (2001) (in English)

13. Oh, K., Jeong, S.-H.: An Assessment of the Spatial Distribution of Urban Parks Using GIS. Journal of the Korea Planners Association 40(3), 189-203 (2005) (in Korean)

14. Park, I.-S., Lee, S.-H., Lim, T.-Y., Song, S.-H., Oh, Y.-J.: Green Enjoyment Indicator of Residential District Reflecting Accessibility and Quantity of Green Area. Research of Seoul \& Other Cities 8(3), 161-172 (2007) (in Korean)

15. Pelizaro, C.: Decision Support Tools - Green space Access and Preference. Eindhoven (2003)

16. Sung, H.-C., Shin, J.-Y.: Strategies to Improve Parks' Accessibility in City: Focus on Gyeonggi-do Region. Journal of the Korean Institute of Landscape Architecture 32(2), 8391 (2005) (in Korean)

17. Tyrväinen, L., Mäkinen, K., Schipperijn, J.: Tools for Mapping Social Values of Urban Woodlands and Other Green Areas. Landscape and Urban Planning 79, 5-19 (2005)

18. Van Herzele, A., Wiedemann, T.: A Monitoring Tool for Provision of Accessible and Attractive Urban Green Spaces. Landscape and Urban Planning 63, 109-126 (2003) 